\title{
The Struggle for Shared Schools in Northern Ireland
}

\section{Michel Savaric}

\section{OpenEdition}

1 Journals

\section{Édition électronique}

URL : http://journals.openedition.org/etudesirlandaises/2086

DOI : 10.4000/etudesirlandaises.2086

ISSN : 2259-8863

\section{Éditeur}

Presses universitaires de Caen

\section{Édition imprimée}

Date de publication : 30 décembre 2010

Pagination : 195-196

ISBN : 978-2-7535-1246-7

ISSN : 0183-973X

\section{Référence électronique}

Michel Savaric, "The Struggle for Shared Schools in Northern Ireland», Études irlandaises [En ligne], 35-2 | 2010, mis en ligne le 30 décembre 2010, consulté le 21 septembre 2020. URL : http://

journals.openedition.org/etudesirlandaises/2086 ; DOI : https://doi.org/10.4000/etudesirlandaises. 2086

Ce document a été généré automatiquement le 21 septembre 2020.

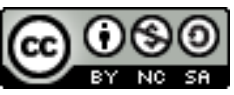

Études irlandaises est mise à disposition selon les termes de la Licence Creative Commons Attribution - Pas d'Utilisation Commerciale - Partage dans les Mêmes Conditions 4.0 International. 


\title{
The Struggle for Shared Schools in Northern Ireland
}

\author{
Michel Savaric
}

\section{RÉFÉRENCE}

Jonathan Bardon, The Struggle for Shared Schools in Northern Ireland: The History of All Children Together, Belfast, Ulster Historical Foundation, 2009, 322 p., ISBN

978-1-903688-87-8

1 Depuis une trentaine d'années, le secteur de l'éducation intégrée en Irlande du Nord connaît un succès soutenu. Ainsi, à la rentrée 2010, la demande était sans précédent et bien supérieure à la capacité d'accueil. Une majorité des établissements secondaires intégrés, dont Lagan College à Belfast et Slemish Integrated à Ballymena, se voyaient contraints de refuser des inscriptions. En juillet 2010, le premier ministre d'Irlande du Nord, Peter Robinson, affirmait au News Letter que les écoles ségréguées engendrent la division et fixait le développement de l'enseignement intégré comme l'une de ses priorités.

2 Pourtant, Jonathan Bardon nous rappelle dans son ouvrage qu'en mai 1981, le même Peter Robinson, élu à la tête de Castlereagh District Council, s'était opposé à la création de Lagan College; ce qui pourrait corroborer l'adage populaire selon lequel seuls les imbéciles ne changent pas d'avis... Bardon nous montre, précisément, que le parcours du mouvement pour l'éducation intégrée, qui reposait sur l'idée simple qu'il fallait éduquer ensemble les enfants catholiques et les enfants protestants, a été long et semé d'embûches. L'historien évoque tout d'abord l'échec des premières tentatives d'intégration scolaire aux dix-neuvième et vingtième siècles : la création d'un système national d'éducation pour l'Irlande en 1830 se heurta à l'opposition des presbytériens, puis des épiscopaliens et des catholiques, de même qu'une nouvelle tentative en Irlande du Nord sous l'égide de Lord Londonderry en 1923. Une autre tentative eut lieu en 1974, sous l'impulsion de Basil McIvor (qui devint plus tard un soutien important du 
mouvement), alors ministre dans le gouvernement issu des accords de Sunningdale, dont l'existence fut brutalement avortée comme on sait.

Puis, il se consacre à l'histoire du mouvement All Children Together. Ce mouvement est parti, en fait, de quelques parents catholiques qui envoyaient leurs enfants dans les écoles «d'État». Ces parents étaient confrontés au problème très concret de l'instruction religieuse de leurs enfants, en particulier de la préparation à la première communion et à la confirmation qui était faite dans les écoles catholiques mais pas en dehors. Il s'est posé, en outre, le problème des évêques qui refusaient ces sacrements aux enfants non scolarisés dans des écoles catholiques. En fait, l'opposition résolue de l'Église catholique a été une constante pendant toute l'histoire du mouvement pour l'intégration.

4 Comme Tony Spencer, lui-même acteur majeur du mouvement, l'avait perçu, l'histoire d'All Children Together peut se résumer en quatre phases. Dans un premier temps, entre 1974 et 1976, l'association tenta de convaincre l'État de créer des établissements intégrés. Devant l'absence de résultats, il se tourna vers les Églises: l'action du mouvement entraîna, en 1978, l'adoption d'une loi sur l'éducation en Irlande du Nord permettant aux Églises de créer des établissements intégrés si elles le désiraient. Bien entendu, rien ne se produisit. Le mouvement décida alors de prendre l'initiative en créant un fonds. Ceci le conduisit à la dernière phase, celle qui fut couronnée de succès : le soutien aux parents d'élèves désireux de créer des établissements scolaires intégrés.

5 Ces premiers établissements furent Lagan College (un établissement secondaire sur le modèle des comprehensive schools anglaises) et Forge Integrated Primary School. Bardon nous narre dans le détail les difficultés considérables auxquelles le mouvement a été confronté pour financer et faire fonctionner ces écoles jusqu'à leur prise en charge par l'État. Le récit s'arrête en 2003 , lorsque l'association a décidé de se dissoudre pour laisser la place à des structures plus officielles. L'ouvrage de Bardon est extrêmement détaillé; il nous donne accès à une masse considérable de documents primaires: affiches et bulletins d'All Children Together, procès-verbaux des assemblées générales, photographies, ainsi que des rapports (croustillants!) d'entrevues entre membres du clergé et ministres.

6 Bardon dresse également un portrait précis des principaux « piliers » du mouvement qui ont porté cette lutte pendant plus de 30 ans. Tous, qu'ils soient catholiques ou protestants, étaient animés d'une profonde foi chrétienne et l'auteur montre bien que le caractère œcuménique du mouvement All Children Together était très marqué. À l'heure où l'Irlande du Nord s'ouvre (un peu) à des influences d'autres parties du monde, on peut s'interroger sur la capacité des établissements intégrés à accueillir ceux qui ne sont pas chrétiens, ainsi qu'à ceux qui n'accordent pas une place centrale à la religion dans leur vie.

7 Quoi qu'il en soit, cet ouvrage nous donne un aperçu d'un mouvement très populaire mais peu connu à l'extérieur de l'Irlande du Nord, une lutte pacifique et exemplaire menée avec ténacité pendant plusieurs décennies dans un contexte extraordinairement peu propice. Le succès actuel de l'enseignement intégré aujourd'hui est riche de paradoxes. Alors que la demande ne cesse de croitre, la ségrégation résidentielle ne cesse de s'intensifier. De même, les tentatives de la ministre Caitriona Ruane (Sinn Féin) pour abolir la sélection des élèves à l'âge d'onze ans ont échoué face à la résistance acharnée des grammar schools. Or, la demande pour les établissements intégrés, qui 
proposent un modèle comprehensive depuis 1981, est telle qu'ils sont devenus parmi les établissements les plus sélectifs d'Irlande du Nord! L'histoire d'All Children Together rédigée par Jonathan Bardon sera d'un grand intérêt pour tout chercheur désireux d'approfondir ces questions. 